\title{
Synthesis of New Fluorene-Indolocarbazole Alternating Copolymers for Light-Emitting Diodes and Field Effect Transistors
}

\author{
By Wen-Ya LEE, ${ }^{1}$ Chien-Wei CHEN, ${ }^{2}$ Chu-Chen CHUEH, ${ }^{1}$ Chang-Chung YANG, ${ }^{3}$ and Wen-Chang CHEN ${ }^{1,2, *}$
}

New alternating copolymers of poly(2,7-(9,9'-dihexylfluorene)-alt-3,9-(5,11-di(2-ethylhexyl)-indolo[3,2-b]carbazole)) (PFp-In) and poly(2,7-(9,9'-dihexylfluorene)-alt-2,8-(5,11-di(2-ethylhexyl)-indolo[3,2-b]carbazole)) (PF-m-In) were synthesized by palladium-catalyzed Suzuki coupling polymerization and characterized for the applications of light-emitting diodes and field effect transistors (FET). The incorporation of indolocarbazole into polyfluorene could not only enhance hole transporting properties but also thermal properties. The para-linkage, PF-p-In, facilitates $\pi$-electron delocalization and thus has a lower optical band gap and a higher emission maximum than those of the meta linkage, PF-m-In. The electroluminescence devices based on PF-p-In and PF-m-In as the emissive layer show a similar maximum luminance but with different emissive colors of green and blue, respectively. The FET hole mobilities of PF-p-In and PF-m-In are $6.73 \times 10^{-5}$ and $1.50 \times 10^{-4} \mathrm{~cm}^{2} / \mathrm{V} \cdot \mathrm{s}$, respectively, which are significantly higher than that of polyfluorene. The present study demonstrates the electronic and optoelectronic properties of polyfluorene enhanced by incorporating hole transporting indolocarbazole with different linkages.

KEY WORDS: Functional Polymers / Polymer Synthesis / Light-Emitting Diodes / Field Effect Transistors / Fluorene / Indolocarbazole /

Conjugated polymers have been extensively studied for various electronic and optoelectronic devices, such as electroluminescence displays, photovoltaic cells, and field effect transistors. $^{1-5}$ Oligo- and polyfluorene as well as their derivatives are excellent candidates for optoelectronic applications because they exhibit high thermal/chemical stability, excellent fluorescence quantum yields, and solution processibility. ${ }^{6,7}$ However, the relatively high ionization potential and low electron affinity of poly(9,9-dialkylfluorene) lead to poor carrier injection from the electrodes. Thus, limited electroluminescence (EL) efficiency and insignificant or no field effect mobility were reported in the literature..$^{8,9}$

The electronic and optoelectronic properties of polyfluorene could be improved through the approaches of copolymer, blend, side chain modification, end-capping, or nanofiber and result in enhanced device characteristics. ${ }^{8-17}$ For example, the copolymers of fluorene with hole transporting moieties of phenothiazine and phenoxazine led to enhanced EL characteristics ${ }^{8}$ and field effect mobility, ${ }^{9}$ respectively. The incorporation of acceptor and donor-acceptor-donor moiety into polyfluorene also successfully improved the EL or FET characteristics. $^{12-15}$ Indolocarbazole-based materials have emerged as new p-type organic semiconductors due to relatively high hole-transporting mobility and photo-oxidative stability. Relatively high hole mobilities of 0.2 and 0.02 $\mathrm{cm}^{2} \mathrm{~V}^{-1} \mathrm{~s}^{-1}$ were reported for the indolo[3,2-b]carbazole ${ }^{18-20}$ and polymer derivatives, ${ }^{21-23}$ respectively. Hence, it would be of interest to explore the synthesis and properties of fluoreneindolocarbazole copolymers.

In this study, new alternating copolymers of 9,9-dihexyl- fluorene and 3,9- or 2,8-substituted di(2-ethylhexyl)-indolo[3,2-b]carbazole were synthesized and characterized. The effects of indolocarbazole and its linkage position on the electronic, photoluminescence, and electrochemical properties of the synthesized copolymers were explored. Electroluminescence and field effect transistor devices based on the synthesized copolymers were also studied and compared with the parent polyfluorenes (PF). The present study suggests that the hole transporting property and device characteristics of polyfluorene are significantly improved by incorporating indolocarbazole.

\section{EXPERIMENTAL}

\section{Reagents and Materials}

1,4-Cyclohexanedione, 3-bromophenylhydrazine hydrochloride, 4-bromophenylhydrazine hydrochloride, 2-ethylhexylbromide, glacial acetic acid, sulfuric acid, 9,9-dihexylfluorene-2,7-bis(trimethyleneborate), tetrakis-(triphenylphosphine)-palladium(0), and potassium carbonate and trioctylmeth-ylammonium chloride (aliquat ${ }^{\circledR}$ 336) were purchased from Aldrich (Missouri, USA) or Acros (Geel, Belgium) and used without further purification. $N, N$-dimethyl-formamide (DMF), N,N-dimethylsulfoxide (DMSO) and ethanol (EtOH) were purchased from Tedia (Ohio, USA). All starting reagents and solvents were used in the reactions under nitrogen. 2,8Dibromo-5,11-di(2'-ethylhexyl)-indolo[3,2-b]carbazole and 3,9dibromo-5,11-di(2'-ethylhexyl)-indolo[3,2-b]carbazole were prepared according to the literature report. ${ }^{23}$

\footnotetext{
${ }^{1}$ Department of Chemical Engineering, National Taiwan University, Taipei, Taiwan 106

${ }^{2}$ Institute of Polymer Science and Engineering, National Taiwan University, Taipei, Taiwan 106

${ }^{3}$ Energy and Environmental Laboratories, Industrial Technology Research Institute, Hsinchu, Taiwan 310

*To whom correspondence should be addressed (Tel: +886-2-23628398, Fax: +886-2-23623040, E-mail: chenwc@ntu.edu.tw).
} 


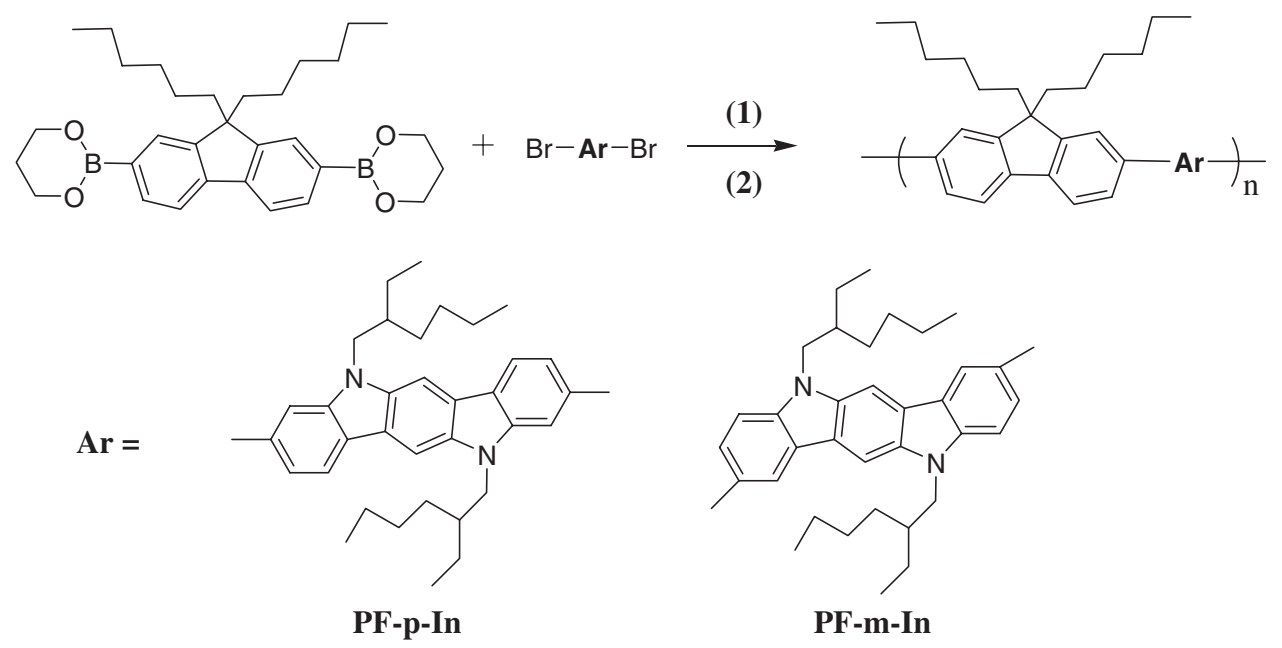

Synthetic routes :

(1) $\mathrm{Pd}\left(\mathrm{PPh}_{3}\right)_{4} / \mathrm{K}_{2} \mathrm{CO}_{3} /$ Toluene

(2) Phenyl boronic acid / Bromobenzene

Scheme 1

General Procedures of the Suzuki Coupling Polymerization

Syntheses of the copolymers were carried out using palladium-catalyzed Suzuki coupling polymerization, as shown in Scheme 1. 9,9-Dihexyl-fluorene-2,7-bis(trimethyleneborate), 2,8-dibromo-5,11-di(2'-ethylhexyl)-indolo[3,2-b]carbazole or 3,9-dibromo-5,11-di(2'-ethylhexyl)-indolo[3,2-b]carbazole), tetrakis(triphenylphosphine)palladium (0) (1 mol \% with respect to diborate monomer), and several drops of aliquat ${ }^{\circledR}$ 336 were dissolved in toluene. To the reaction mixture, degassed aqueous $2 \mathrm{M} \mathrm{K}_{2} \mathrm{CO}_{3}$ (3.3 equiv. with respect to the diborate monomer) was added. The mixture was refluxed with vigorous stirring for $72 \mathrm{~h}$ under a nitrogen atmosphere. The end groups were capped by refluxing with phenyl boronic acid and bromobenzene (both 1.1 equiv. with respect to diborate monomer) for $12 \mathrm{~h}$ each. After end capped, the reaction mixture was cooled and poured into a mixed solvent of methanol and water. The precipitated product was dissolved into a small amount of THF and then re-precipitated into methanol to afford a crude polymer. The crude polymer was washed with acetone for $24 \mathrm{~h}$ to remove oligomers and catalyst residues.

Poly[2,7-(9,9' -dihexylfluorene)-alt-3,9-(5,11-di(2-ethylhexyl)indolo[3,2-b]carbazole)] (PF-p-In). 9,9-Dihexylfluorene-2,7bis(trimethyleneborate) $(502 \mathrm{mg} ; 1 \mathrm{mmol})$ and 3,9-dibromo5,11-di(2'-ethylhexyl)-indolo[3,2-b]carbazole (638 mg; $1 \mathrm{mmol})$ were dissolved in $10 \mathrm{~mL}$ of anhydrous toluene under nitrogen atmosphere. The final product, a yellow-green polymer with a yield of $560 \mathrm{mg}(70.3 \%)$, was obtained after drying in vacuum at $80{ }^{\circ}$ C. Anal. Calcd (wt \%) for $\left(\mathrm{C}_{58} \mathrm{H}_{72} \mathrm{~N}_{2}\right)_{\mathrm{n}}$ : C, 87.16; $\mathrm{H}$, 9.33; N, 3.51. Found: C, 85.03, H, 9.13, N, 3.32. FT/IR ( $\mathrm{KBr}$ pellet, $\left.\mathrm{cm}^{-1}\right)$ : 2956 ( $-\mathrm{CH}_{3}$ stretching), 1465 ( $-\mathrm{CH}_{2}-$ bending). ${ }^{1} \mathrm{HNMR}\left(300 \mathrm{MHz}, \mathrm{CDCl}_{3}, \mathrm{ppm}\right): 8.30(2 \mathrm{H}) ; 8.04(2 \mathrm{H}) ; 7.87$ $(2 \mathrm{H}) ; 7.78(4 \mathrm{H}) ; 7.69(2 \mathrm{H}) ; 7.59(2 \mathrm{H}) ; 4.38(4 \mathrm{H}) ; 2.29(2 \mathrm{H})$; $2.16(4 \mathrm{H}) ; 1.35(8 \mathrm{H}) ; 1.25(4 \mathrm{H}) ; 1.13(16 \mathrm{H}) ; 0.91(10 \mathrm{H}) ; 0.78$
(10H). GPC: $M_{\mathrm{n}}$ (the number-average molecular weight): 8800 and PDI (polydispersity index): 1.34 .

Poly[2,7-(9,9'-dihexylfluorene)-alt-2,8-(5,11-di(2-ethylhexyl)indolo[3,2-b]carbazole)] (PF-m-In). 9,9-Dihexylfluorene-2,7bis(trimethyleneborate) $(502 \mathrm{mg} ; 1 \mathrm{mmol})$ and 2,8-dibromo5,11-di(2'-ethylhexyl)-indolo[3,2-b]carbazole (638 mg; $1 \mathrm{mmol})$ were dissolved in $10 \mathrm{~mL}$ of anhydrous toluene under nitrogen for $10 \mathrm{~min}$. The final product, a yellow-green polymer with a yield of $586 \mathrm{mg}$ (73.5\%), was obtained after drying in vacuum at $80{ }^{\circ}$ C. Anal. Calcd $(w t \%)$ for $\left(\mathrm{C}_{58} \mathrm{H}_{72} \mathrm{~N}_{2}\right)_{\mathrm{n}}$ : C, 87.16; $\mathrm{H}$, 9.33; N, 3.51. Found: C, 86.88, H: 8.40; N, 3.30. FT/IR ( $\mathrm{KBr}$ pellet, $\left.\mathrm{cm}^{-1}\right)$ : $2952\left(-\mathrm{CH}_{3}\right.$ stretching), $1463\left(-\mathrm{CH}_{2}-\right.$ bending $)$. ${ }^{1} \mathrm{H} \mathrm{NMR}\left(300 \mathrm{MHz}, \mathrm{CDCl}_{3}\right.$, ppm): $8.48(2 \mathrm{H}) ; 8.10(2 \mathrm{H}) ; 7.83$ $7.78(6 \mathrm{H}) ; 7.55(2 \mathrm{H}) ; 7.49(2 \mathrm{H}) ; 4.34(4 \mathrm{H}) ; 2.25(2 \mathrm{H}) ; 2.11$ $(4 \mathrm{H}) ; 1.34(8 \mathrm{H}) ; 1.23(4 \mathrm{H}) ; 1.13(16 \mathrm{H}) ; 0.92(10 \mathrm{H}) ; 0.78$ $(10 \mathrm{H})$. GPC: $M_{\mathrm{n}}$ (the number-average molecular weight): 5700 and PDI (polydispersity index): 2.07.

\section{Characterization Methods}

${ }^{1} \mathrm{H}$ NMR spectra were measured on a Bruker AV $500 \mathrm{MHz}$ spectrometer using $\mathrm{CDCl}_{3}$ as the solvent and tetramethylsilane as internal reference. Fourier transform infrared spectrometer was measured in a Perkin Elmer FT/IR spectrometer 100. Weight-average molecular weights and number-average molecular weights were obtained via size exclusion chromatography (SEC) on the basis of polystyrene calibration using a Water 2410 apparatus and tetrahydrofuran (THF) as the eluent. Elemental analyses were run in a Heraeus Vario-III analyzer.

Thermogravimetric analysis (TGA) was conducted with a pyris 1 TGA. Experiments were carried out on 3-6 mg samples heated under nitrogen atmosphere at a heating rate of $20^{\circ} \mathrm{C} /$ min. Differential scanning calorimetry (DSC) was performed on a TA instrument DSC-910S differential scanning calorim- 
eter under nitrogen atmosphere at a heating rate of $10^{\circ} \mathrm{C} / \mathrm{min}$. UV-visible absorption and photoluminescence (PL) spectra were obtained on a Jasco model UV/VIS/NIR V-570 spectrometer and Fluorolog-3 spectrofluorometer (Jobin Yvon), respectively. For the solution spectra, polymers were dissolved in THF ( $c$ a. $10^{-6} \mathrm{M}$ ) and then put in a quartz cell for measurement. For the thin film spectra, polymers were first dissolved in THF $(1 \mathrm{wt} \%)$ and then spin-coated on glass substrate at $1000 \mathrm{rpm}$ for $30 \mathrm{~s}$. Then, the thin films were dried at $60{ }^{\circ} \mathrm{C}$ under vacuum. Films used for the PL efficiency measurement were drop-coated from THF solution onto quartz substrates ( $c a .1 \mathrm{wt} \%)$. PL efficiencies of the films on quartz substrates were measured by fluorolog 3 . The electrochemical properties of the polymer films were investigated on a Princeton Applied Research Model 273A Potentiostat/Galvanostat with a $0.1 \mathrm{M}$ acetonitrile solution containing tetrabutylammonium tetrafluoroborate $\left(\mathrm{TBABF}_{4}\right)$ as the electrolyte. Platinum wire and rod-tip electrodes were used as counter and working electrodes respectively. Silver/silver ion (Ag in $0.1 \mathrm{M} \mathrm{AgNO}_{3}$ in the supporting electrolyte solutions) was used as a reference electrode. A $3 \mathrm{wt} \%$ solution of a polymer in THF was used to prepare the polymer film on the Pt rod-tip electrode. Then, the cyclic voltammetry of films was performed on a three-electrode cell.

\section{Polymer Light-Emitting Devices (LED)}

The polymer LED devices were fabricated in the configuration of ITO/poly(ethylene dioxythiophene):poly(styrenesulfonate) (PEDOT:PSS) $(50-60 \mathrm{~nm}) /$ light-emitting layer (70$80 \mathrm{~nm}) / \mathrm{Ca}(10 \mathrm{~nm}) / \mathrm{Ag}(100 \mathrm{~nm})$. Onto the ITO glass a layer of poly(ethylene dioxythiophene):poly(styrene sulfonate) (PEDOT:PSS), 50-60 nm thick (probed by Alpha-Step ${ }^{\circledR} 500$ Surface Profiler), was formed by spin-coating from its aqueous solution (Baytron P 8000, Bayer) to enhance the hole injection and the smoothness between layers. The light-emitting layer was spin-coated on top of the PEDOT:PSS layer from the corresponding filtered toluene solution $(1.5 \mathrm{wt} \%)$ and also dried under vacuum. Under a base pressure below $2 \times 10^{-6}$ Torr, a layer of $\mathrm{Ca}(10 \mathrm{~nm})$ was vacuum deposited as cathode and a thick layer of $\mathrm{Ag}(100 \mathrm{~nm})$ was deposited subsequently as the protecting layer. The current-voltage-luminance characteristics were measured using a computerized Keithley 2400 source meter and Konica-Minolta Chroma Meter CS-100A. The EL spectrum of device was recorded on Fluorolog-3 spectrofluorometer (Jobin Yvon).

\section{Polymer Field Effect Transistors}

The field effect transistor was fabricated from the PF-p-In or PF-m-In with a bottom-contact configuration on the pdoped silicon wafers. A thermally grown $200 \mathrm{~nm} \mathrm{SiO} 2$ used as the gate dielectric with a capacitance of $17 \mathrm{nF} / \mathrm{cm}^{2}$. Aluminum was used to create a common bottom-gate electrode. The source/drain regions were defined by a $10 \mathrm{~nm}$ thick chromium adhesion layer and a $100 \mathrm{~nm}$ thick gold contact electrode through a regular shadow mask, and the channel length (L) and width (W) were 25 and 500 (or 1000) $\mu \mathrm{m}$, respectively.
Afterward, the substrate was modified with octyltrichlorosilane (OTS) as silane coupling agents. In order to fabricate good quality thin films, PF-p-In and PF-m-In were dissolved in toluene, respectively. The $0.5 \mathrm{wt} \%$ polymer solutions were filtered through $0.20 \mu \mathrm{m}$ pore size of PTFE membrane syringe filters. The solutions were then spin-coated at a speed rate of $1000 \mathrm{rpm}$ for $60 \mathrm{~s}$ onto the OTS modified $\mathrm{SiO}_{2} / \mathrm{Si}$ substrate and heated at $60^{\circ} \mathrm{C}$ for $12 \mathrm{~h}$ in $\mathrm{N}_{2}$. Output and transfer characteristics of the FET devices were measured using Keithley 4200 semiconductor parametric analyzer in ambient atmosphere.

\section{RESULTS AND DISCUSSION}

\section{Polymer Structures}

Figure 1 shows the ${ }^{1} \mathrm{H}$ NMR spectrum of PF-p-In in $\mathrm{CDCl}_{3}$. The peaks at $7.53-8.30 \mathrm{ppm}$ are assigned to the phenylene protons of indolocabazole and fluorene backbone. The peaks at 2.14 and $4.38 \mathrm{ppm}$ are assigned to the methylene protons adjacent to fluorene 9-position and indolocarbazole N-position, respectively. The ${ }^{1} \mathrm{H}$ NMR spectrum of PF-m-In also agrees well with the proposed structure, as shown in the supporting information (Figure S1). The FT/IR spectra of PF-p-In and PF-m-In exhibit the expected $\mathrm{CH}_{2}, \mathrm{CH}_{3}$, and $\mathrm{C}-\mathrm{N}$ vibration band, as exhibited in Figure S2 of the supporting information. The difference between the experimental and theoretical carbon contents from the elemental analysis is probably due to the end group effect from the low molecular weights of the prepared polymers. The two copolymers are soluble in common solvents, such as chloroform and THF at room temperature. The numberaverage molecular weights and polydispersity index $\left(M_{\mathrm{n}}, \mathrm{PDI}\right)$ of PF-p-In and PF-m-In are (8800, 1.34), and (5700, 2.07), respectively. The above results suggest that the successful preparation of the target copolymers.

\section{Thermal Properties}

Figure 2 shows the DSC curves of PF-p-In and PF-m-In, in which the TGA curves are shown in the insert figure. The thermal decomposition temperatures $\left(T_{\mathrm{d}}\right)$ of PF-p-In and PFm-In under nitrogen atmospheres are 417 and $449^{\circ} \mathrm{C}$, respectively. The char yield is more than $53 \%$ at $800{ }^{\circ} \mathrm{C}$ under nitrogen. The glass transition temperatures $\left(T_{\mathrm{g}}\right)$ of PF-p-In and PF-m-In are 109 and $156^{\circ} \mathrm{C}$, respectively. Note that the $T_{\mathrm{d}}$ and $T_{\mathrm{g}}$ of the polyfluorene (PF) homopolymer are 409 and $67^{\circ} \mathrm{C} .{ }^{13}$ The higher thermal stability of the PF-p-In and PF-m-In than that of $\mathbf{P F}$ is due to the incorporation of ladder-like indolocarbazole backbone into polymer structure. The higher $T_{\mathrm{g}}$ of the PF-m-In than that of PF-p-In could be due to the less rotational freedom of the former because of the steric hindrance on the meta-position structure. ${ }^{24}$

\section{Electronic and Optoelectronic Properties}

The photophysical properties of PF-p-In and PF-m-In in solutions and solid state films are summarized in Table I. Figure 3 shows the normalized UV-vis absorption and photoluminescence spectra of PF-p-In and PF-m-In in solid state 


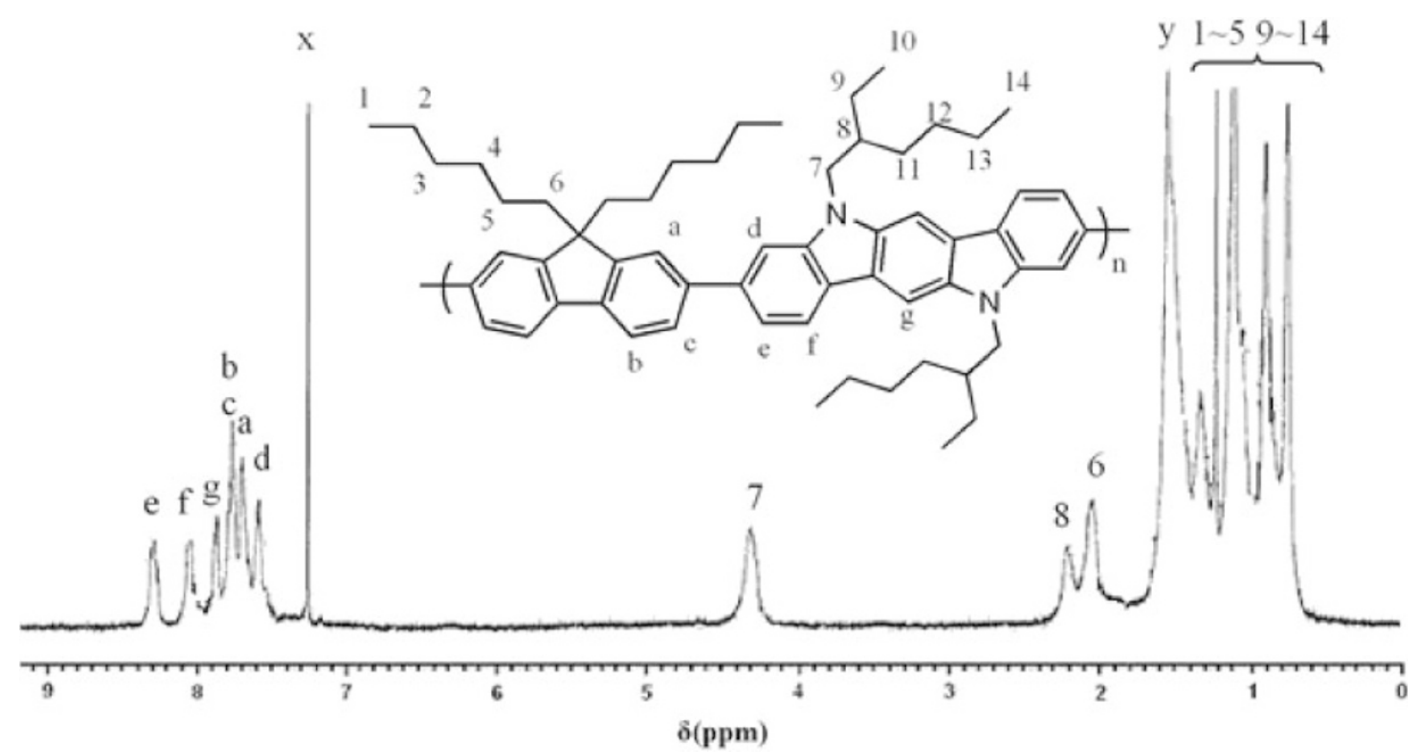

Figure 1. ${ }^{1} \mathrm{HNMR}$ spectra of PF-p-In in $\mathrm{CDCl}_{3}$. The labels of $\mathrm{x}$ and $\mathrm{y}$ are $\mathrm{CDCl}_{3}$ and $\mathrm{H}_{2} \mathrm{O}$, respectively.

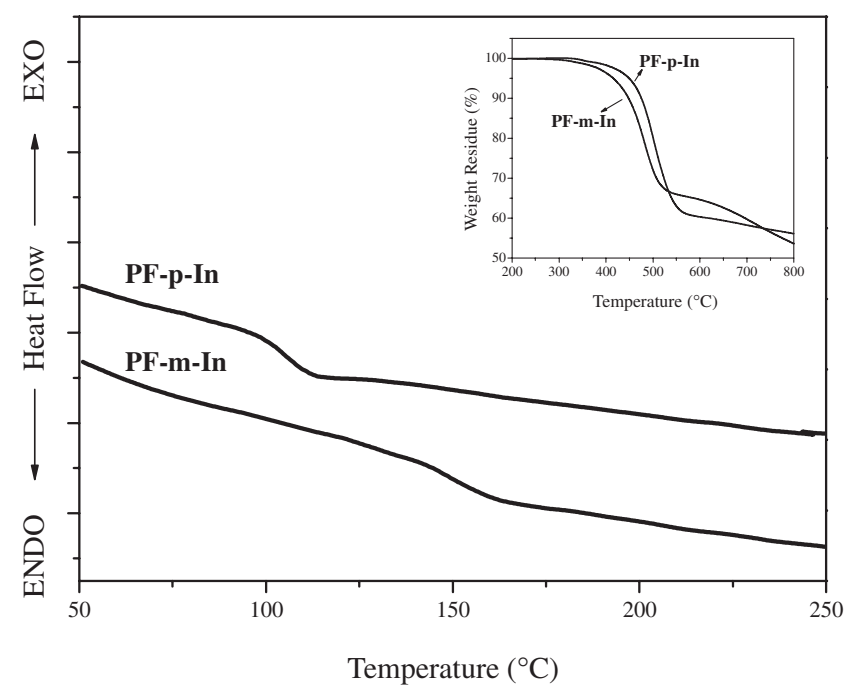

Figure 2. DSC curves of PF-p-In and PF-m-In at a heating rate of $20^{\circ} \mathrm{C} / \mathrm{min}$ under a nitrogen atmosphere. The insert figure shows TGA curves of PF-p-In and PF-m-In at a heating rate of $20^{\circ} \mathrm{C} / \mathrm{min}$ under a nitrogen atmosphere.

films. The normalized PL and UV-vis spectra are obtained through the ratio of absorption or fluorescence intensity at different wavelength to the maximum intensity. The optical absorption maxima ( $\left.\lambda_{\text {abs, max }}\right)$ of PF-p-In and PF-m-In in solid state films are 391 and $363 \mathrm{~nm}$, respectively, while the corresponding optical band gaps $(\mathrm{eV})$ estimated from the absorption edges are 2.78 and $2.87 \mathrm{eV}$, respectively. The solution spectra of the above two polymers also show a similar trend on the linkage effect of the photophysical properties. The para-linkage, PF-p-In, facilitates the $\pi$-electron delocalization and results in a lower band gap than the meta-linkage, PF-mIn. The extended tails and/or shoulders near the absorption edges of PF-p-In and PF-m-In suggest stronger inter-chain interaction as compared to the parent PF. The optical band gaps of PF-p-In and PF-m-In are smaller than that of polyfluorene (PF) with $2.95 \mathrm{eV}$, due to the incorporation of the highly conjugated indolocarbazole.

The higher emission maximum $\left(\lambda_{\mathrm{PL}, \max }\right)$ of PF-p-In at $500 \mathrm{~nm}$ than that of PF-m-In with $468 \mathrm{~nm}$ in Figure 3 is resulted from the lower band gap of the former due to the paralinkage. The solution photoluminescence spectra also show a similar trend. Both polymers have a high emission maxima than those of PF with (424 and $445 \mathrm{~nm}$ ) reported previously, ${ }^{13}$ due to the lower band gap of the former.

Figure 4 shows the cyclic voltammograms of PF-p-In and PF-m-In and the corresponding electrochemical results are listed in Table I. The onset oxidation $\left(\mathrm{E}_{\text {onset }}\right)$ of PF-p-In

Table I. Optical and Electrochemical Properties of PF-p-In and PF-m-In

\begin{tabular}{|c|c|c|c|c|c|c|c|c|c|}
\hline \multirow[b]{2}{*}{ Polymer } & \multicolumn{2}{|c|}{ Solution (THF) } & \multicolumn{3}{|c|}{ Film } & \multicolumn{2}{|c|}{$\begin{array}{l}\text { Oxidation (V) } \\
\text { (v.s. Ag/AgCl) }\end{array}$} & \multirow[b]{2}{*}{$\begin{array}{l}\text { HOMO } \\
(e V)^{d}\end{array}$} & \multirow[b]{2}{*}{$\begin{array}{l}\text { LUMO } \\
(\mathrm{eV})^{\mathrm{e}}\end{array}$} \\
\hline & $\begin{array}{c}\lambda_{\mathrm{abs}, \max } \\
(\mathrm{nm})\end{array}$ & $\begin{array}{l}\lambda_{\mathrm{PL}, \max } \\
(\mathrm{nm})\end{array}$ & $\begin{array}{l}\lambda_{\mathrm{abs}, \max } \\
\quad(\mathrm{nm})\end{array}$ & $\begin{array}{l}\mathrm{Eg}^{\mathrm{opt}} \\
(\mathrm{eV})^{\mathrm{a}}\end{array}$ & $\begin{array}{c}\text { Quantum } \\
\text { yield } \\
(\%)\end{array}$ & $\begin{array}{l}E_{1 / 2} \\
(V)^{b}\end{array}$ & $\begin{array}{c}E_{\text {onset }} \\
(V)^{c}\end{array}$ & & \\
\hline PF-p-In & 392 & 457,487 & 391 & 2.78 & 33 & 0.87 & 0.74 & -5.10 & -2.32 \\
\hline PF-m-In & 357 & 437,463 & 363 & 2.87 & 29 & 0.93 & 0.87 & -5.23 & -2.36 \\
\hline
\end{tabular}

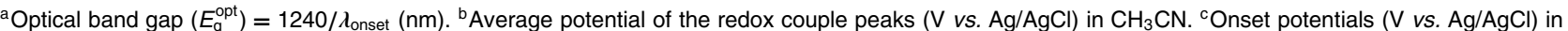
$\mathrm{CH}_{3} \mathrm{CN}$. ${ }^{\mathrm{d}}$ The $\mathrm{HOMO}$ energy levels were calculated from cyclic voltammetry and were referenced to ferrocene $(4.8 \mathrm{eV})$. ${ }^{\mathrm{e}} \mathrm{No}$ reduction potential was observed in the CV. Thus, the LUMO level was estimated by the following relation: $E_{\mathrm{LUMO}}=E_{\mathrm{HOMO}}+E_{\mathrm{g}}^{\mathrm{opt}}$. 


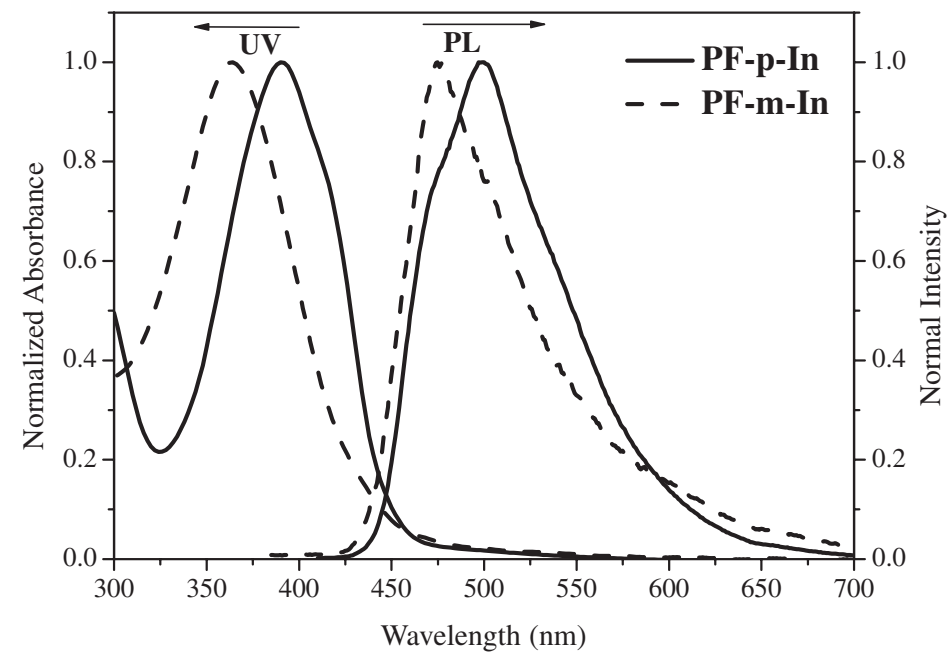

Figure 3. UV-vis absorption and photoluminescence spectra of PF-p-In and PF-m-In films on quartz substrates.

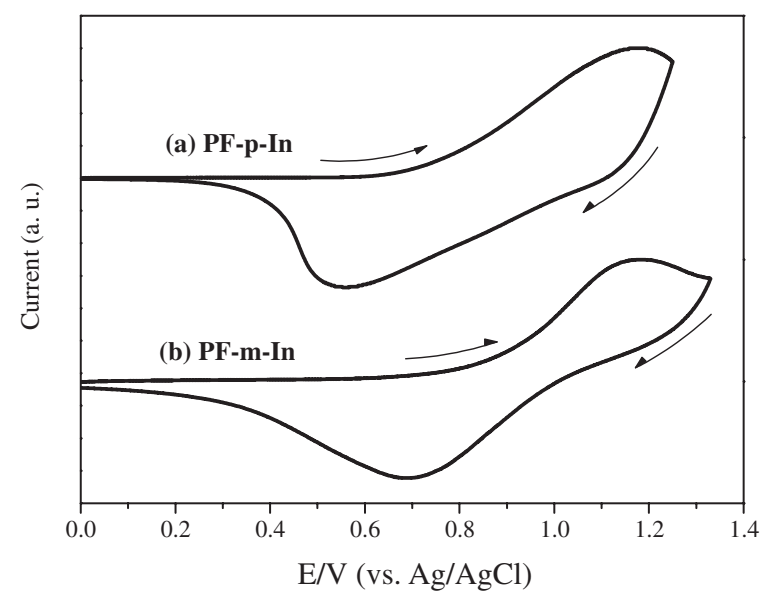

Figure 4. Cyclic voltammograms of (a) PF-p-In and (b) PF-m-In at scan rate $=100 \mathrm{mV} / \mathrm{s}$. The films in a $0.1 \mathrm{M}$ acetonitrile solution containing tetrabutylammonium tetrafluoroborate $\left(\mathrm{TBABF}_{4}\right)$ as the electrolyte. Note that anodic current is taken as positive and positive potential is plotted to the right.

is $0.74 \mathrm{~V}$ vs $\mathrm{Ag} / \mathrm{AgCl}$. The ferrocene/ferrocenium $\left(\mathrm{Fc} / \mathrm{Fc}^{+}\right)$ redox standard $E_{1 / 2}$ is $0.44 \mathrm{~V}$ vs $\mathrm{Ag} / \mathrm{AgCl}$ in $\mathrm{CH}_{3} \mathrm{CN}$. Assuming that the energy for the $\mathrm{Fc} / \mathrm{Fc}^{+}$standard is $4.8 \mathrm{eV}$ with respect to the zero vacuum level, ${ }^{25}$ the ionization potential (IP) for PF-p-In is estimated to be $5.10 \mathrm{eV}$ (IP $=\mathrm{E}_{\text {onset }}-$ $0.44+4.8)$. Thus, the corresponding HOMO level of PF-p-In is $-5.10 \mathrm{eV}$ from the relation of $\mathrm{HOMO}=-\mathrm{IP}$. Similarly, the HOMO level of PF-m-In is estimated to be $-5.23 \mathrm{eV}$. The
HOMO level of the PF reported previously ${ }^{13}$ is at $-5.39 \mathrm{eV}$. It suggests that the hole transporting property of $\mathbf{P F}$ is improved by incorporating indolocabazole. The lower HOMO energy level of the PF-p-In than that of PF-m-In probably results from the better $\pi$ electron delocalization of the former.

\section{Electroluminescence Properties of LED Devices}

The LED devices with the studied copolymers as emissive layers were fabricated with configuration of ITO/PEDOT: PSS/emissive polymer/Ca/Ag. The emission characteristics of the above devices are listed in Table II. Figure 5 shows the EL spectra of PF-p-In and PF-m-In measured at maximum luminance yield. As shown in the Figure 5, the emission characteristics of PF-p-In and PF-m-In are quite different because of the different linking position between fluorene and indolocarbazole. The emission maxima of PF-p-In and PF-mIn are 498 and $467 \mathrm{~nm}$, respectively. The blue-shifted EL spectrum of PF-m-In with respect to PF-p-In is resulted from the larger energy band gap of PF-m-In, since the meta linkage has a shorter $\pi$-conjugation length. It suggests that the emission color could be tuned through different linkages.

The relatively low turn-on voltages (5-6 V) of PF-p-In and PF-m-In are due to the higher HOMO energy levels and the better hole transporting properties by incorporating indolocarbazole into PF. Note that the turn-on voltage of the PF device is around $10 \mathrm{~V} .{ }^{13}$ The PF-p-In and PF-m-In device have maximum luminance intensities of 219 and $181 \mathrm{~cd} / \mathrm{m}^{2}$, respectively. It indicates that the maximum luminance inten-

Table II. Electroluminescence characteristics of PF-p-In and PF-m-In

\begin{tabular}{|c|c|c|c|c|c|c|c|}
\hline \multirow[t]{2}{*}{ Polymer } & \multirow{2}{*}{$\begin{array}{c}\lambda_{\max }{ }^{\mathrm{EL}} \\
(\mathrm{nm})\end{array}$} & \multirow{2}{*}{$\begin{array}{l}\text { Bias } \\
(\mathrm{V})\end{array}$} & \multirow{2}{*}{$\begin{array}{c}\text { Current } \\
\text { density } \\
\left(\mathrm{mA} / \mathrm{cm}^{2}\right)\end{array}$} & \multirow{2}{*}{$\begin{array}{l}\text { Luminance } \\
\left(\mathrm{cd} / \mathrm{m}^{2}\right)\end{array}$} & \multirow{2}{*}{$\begin{array}{l}\text { Luminance } \\
\text { yield } \\
\text { (cd/A) }\end{array}$} & \multicolumn{2}{|c|}{$\begin{array}{l}\text { Chromaticity } \\
\text { Coordinate }^{b}\end{array}$} \\
\hline & & & & & & $x$ & $y$ \\
\hline PF-p-In & 498 & 11 & 386.1 & 219 & 0.057 & 0.241 & 0.426 \\
\hline PF-m-In & $446^{*}, 467$ & 12 & 290.6 & 181 & 0.062 & 0.191 & 0.229 \\
\hline
\end{tabular}

Device Structure: ITO/PEDOT:PSS/Emissive Layer/Ca/Ag. Measured at maximum luminance yield. ${ }^{a}$ Active area is $0.1256 \mathrm{~cm}^{2}$. ${ }^{\mathrm{b}} \mathrm{The} \mathrm{commission}$ Internationale de L'Eclairage (CIE) 1931 coordinates. *Emission shoulder. 


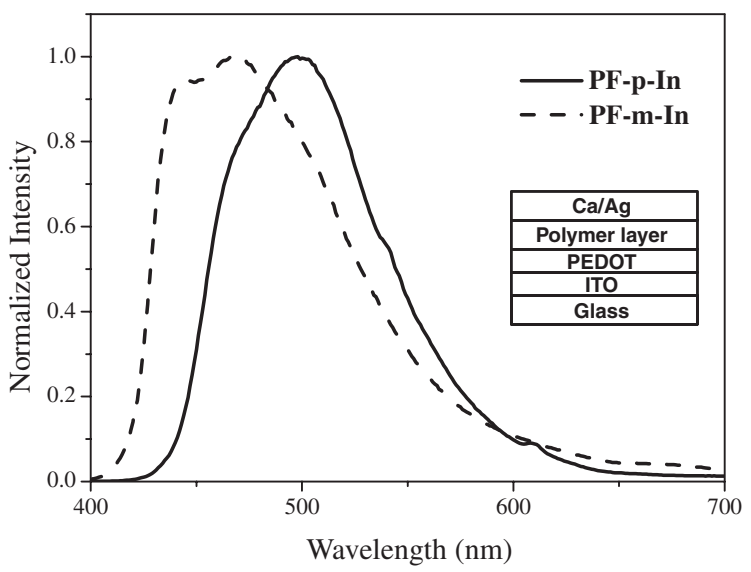

Figure 5. Electroluminescence spectra of PF-p-In and PF-m-In measured at maximum luminance yield based on the device structure of ITO/ PEDOT:PSS/emissive polymer/Ca/Ag.

sities of the devices are not obviously affected by the different linkages (para- or meta-) between fluorene and indolocarbazole except the emission color. The commission Internationale de L'Eclairage (CIE) 1931 coordinates of the EL devices with PFp-In, and PF-m-In measured at maximum luminance yield are $(0.241,0.426)$ and $(0.191,0.229)$, with the corresponding emissive colors of green and blue. These results suggest that the color tuning and enhancement of device performances could be accomplished with incorporating the hole-transporting indolocarbazole into polyfluorene.

\section{Field-effect Transistor (FET) Characteristics}

Figure 6 exhibits typical p-channel transfer characteristics (drain current $\left(\mathrm{I}_{\mathrm{d}}\right)$ versus drain voltage $\left(\mathrm{V}_{\mathrm{d}}\right)$ at various gate voltage $\left(\mathrm{V}_{\mathrm{g}}\right)$ ) of PF-p-In and PF-m-In FETs. In the saturation region $\left(V_{d}>V_{g}-V_{t}\right)$, where $V_{t}$ is the threshold voltage, $I_{d}$ can be described by equation (1): ${ }^{26}$

$$
\mathrm{I}_{\mathrm{d}}=\frac{\mathrm{WC}_{\mathrm{o}} \mu_{\mathrm{h}}}{2 \mathrm{~L}}\left(\mathrm{~V}_{\mathrm{g}}-\mathrm{V}_{\mathrm{t}}\right)^{2}
$$

Where $\mu_{\mathrm{h}}$ is the hole mobility, $\mathrm{W}$ is the channel width, $\mathrm{L}$ is the channel length, and $\mathrm{C}_{0}$ is the capacitance of the gate insulator per unit area, respectively. The saturation region mobility of the studied polymers is calculated from the transfer characteristics of FETs. The hole mobilities of PF-p-In and PF-m-In estimated from Figure 6 and equation (1) are $6.73 \times$ $10^{-5}$ and $1.50 \times 10^{-4} \mathrm{~cm}^{2} / \mathrm{V} \cdot \mathrm{s}$, respectively. The on-off ratios are $7 \times 10^{2}$ and $4 \times 10^{2}$. The hole mobility of PF-m-In is clearly higher than PF-p-In. PF-m-In with the 2,8-linkages could provide more resonance stabilization to the ammonium cation, and aid the process of charge transport. ${ }^{18,21}$ However, such resonance stabilization could not be supplied by PF-p-In. Therefore, the performance of charge transporting characteristics of PF-m-In is better than that of PF-p-In. No FET hole mobility is observed for PF. It suggests that the incorporation of indolocarbazole segments into polyfluorene could enhance charge carrier mobility. Besides, the fluorene-indolocarbazole copolymer based FET devices have the threshold voltage about

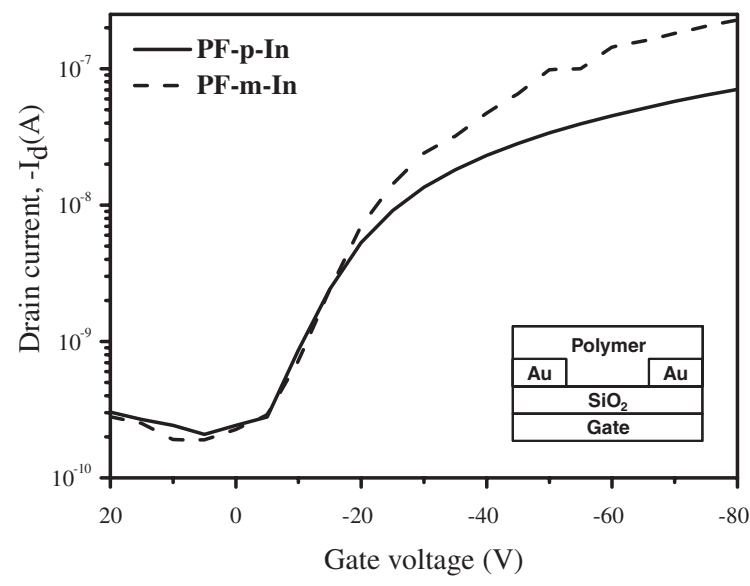

Figure 6. The transfer characteristics (drain current $\left(I_{d}\right)$ versus drain voltage $\left(\mathrm{V}_{\mathrm{d}}\right)$ at various gate voltage $\left(\mathrm{V}_{\mathrm{g}}\right)$ ) of PF-p-In and PF-m-In based field effect transistors.

$-3 \mathrm{~V}$. It indicates that the energy barrier of injection between $\mathrm{Au}$ and polymers is small since the HOMO energy levels of the polymers are very close to the working function of $\mathrm{Au}(5.1 \mathrm{eV})$.

\section{CONCLUSIONS}

The charge transporting characteristics and electroluminescence properties of two new fluorene-indolocarbazole alternating copolymers with different linkage position are reported in this study. The para-linkage PF-p-In has a low optical band gap and higher emission maximum than those of the metalinkage PF-m-In. The FET hole mobilities of PF-p-In and PF-m-In are significantly higher than that of polyfluorene. Besides, the PF-m-In could provide sufficient resonance stabilization and thus higher FET performance than PF-p-In. The present study exhibits the significance of the indolocarbazole moiety and backbone linkages (2,8- or 3,9-linkages) on the electronic and optoelectronic properties of the fluorene-indolocarbazole copolymers.

Acknowledgment. The financial support from National Science council of Taiwan, Ministry of Education, and Ministry of Economics Affairs are highly appreciated.

Electronic Supporting Information Available: Figures S1 and S2. These materials are available via. the Internet at http:// www.spsj.or.jp/c5/pj/pj.htm.

Received: September 14, 2007

Accepted: December 3, 2007

Published: January 17, 2008

\section{REFERENCES}

1. A. Kraft, A. C. Grimsdale, and A. B. Holmes, Angew. Chem. Int. Ed., 37, 402 (1998).

2. L. L. Chua, J. Zaumseil, J. F. Chang, E. C.-W. Ou, P. K.-H. Ho, H. Sirringhaus, and R. H. Friend, Nature, 434, 194 (2005).

3. G. Yu, J. Gao, J. C. Hummelen, F. Wudl, and A. J . Heeger, Science, 
270, 1789 (1995).

4. G. Li, V. Shrotriya, J. Huang, Y. Yao, T. Moriarty, K. Emery, and Y. Yang, Nature Mater., 4, 864 (2005).

5. S. Seki and S. Tagawa, Polym. J., 39, 277 (2007).

6. U. Scherf and E. J. W. List, Adv. Mater., 14, 477 (2002).

7. D. Neher, Macromol. Rapid Commun., 22, 1365 (2001).

8. A. P. Kulkarni, X. Kong, and S. A. Jenekhe, Macromolecules, 39, 8699 (2006).

9. Y. Zhu, A. Babel, and S. A. Jenekhe, Macromolecules, 38, 7983 (2005).

10. S. Xiao, M. Nguyen, X. Gong, Y. Cao, H. Wu, D. Moses, and A. J. Heeger, Adv. Funct. Mater., 13, 25 (2003).

11. W. J. Lin, W. C. Chen, W.-C. Wu, Y. H. Niu, and A. K. Y. Jen, Macromolecules, 37, 2335 (2004).

12. W. C. Wu and W. C. Chen, J. Polym. Res., 13, 441 (2006).

13. W. C. Wu, C. L. Liu, and W. C. Chen, Polymer, 47, 527 (2006).

14. Q. Peng, J. B. Peng, E. T. Kang, K. G. Neoh, and Y. Cao, Macromolecules, 38, 7292 (2005).

15. W. Y. Lee, K. F. Chang, T. F. Wang, C. C. Chueh, W. C. Chen, C. S. Tuan, and J. L. Lin, Macromol. Chem. Phys., 208, 1919 (2007).

16. C. C. Kuo, J. H. Lin, and W. C. Chen, Macromolecules, 40, 6959
(2007).

17. K. Takagi, K. Saiki, K. Mori, Y. Yuki, and M. Suzuki, Polym. J., 39, 813 (2007).

18. Y. Li, Y. Wu, S. Gardner, and B. S. Ong, Adv. Mater., 17, 849 (2005).

19. Y. Wu, Y. Li, S. Gardner, and B. S. Ong, J. Am. Chem. Soc., 127, 614 (2005).

20. P.-L. Boudreau, S. Wakim, S. N. Blouin, M. Simard, C. Tessier, Y. Tao, and M. Leclerc, J. Am. Chem. Soc., 129, 9125 (2007).

21. Y. Li, Y. Wu, and B. S. Ong, Macromolecules, 39, 6521 (2006).

22. N. Blouin, A. Michaud, S. Wakim, P.-L. T. Boudrealt, M. Leclerc, B. Vercelli, S. Zecchin, and G. Zotti, Macromol. Chem. Phys., 207, 166 (2006).

23. N. Blouin, M. Leclerc, B. Vercelli, S. Zecchin, and G. Zotti, Macromol. Chem. Phys., 207, 175 (2006).

24. Y. K. Jung, J. Lee, S. K. Lee, H.-J. Cho, and H.-K. Shim, J. Polym. Sci., Part A: Polym. Chem., 44, 4611 (2006).

25. G. S. Liou, S. H. Hsiao, W. C. Chen, and H.-J. Yen, Macromolecules, 39, 6036 (2006).

26. Z. Bao, A. Dodabalapur, and A. J. Lovinger, Appl. Phys. Lett., 69 4108 (1996). 